\title{
Distorções científicas perenes e suas consequências para o ensino de ciências: a relação entre eletricidade, magnetismo e calor
} \author{
electricity, magnetism and heat \\ Ana Paula Bispo da Silva*10 \\ ${ }^{1}$ Universidade Estadual da Paraíba, Campina Grande, PB, Brasil
}

Perennial scientific distortions and their consequences to science teaching: the relationship among

\begin{abstract}
Recebido em 07 de Novembro, 2018. Revisado em 11 de Fevereiro, 2019. Aceito em 28 de Fevereiro, 2019.
\end{abstract}
\begin{abstract}
Distorções históricas podem levar a uma compreensão errada da ciência e trazer consequências indesejadas para o ensino de ciências. Neste trabalho trazemos um estudo de caso histórico em que uma modificação, por conveniência, na descrição de uma pesquisa acabou ocasionando uma distorção conceitual e procedimental que perdura na história. Trata-se de um exemplo de que atribuir fatos, conceitos e fórmulas a um personagem da história tem implicações maiores do uma simples ilustração.
\end{abstract}

Palavras-chave: Efeito Seebeck, Oersted, Experimentos Históricos.

\begin{abstract}
Historical distortions can promote a misunderstanding on science and to bring undesirable consequences to science teaching. In this work, we discuss a historical case study in which the description of a research was conveniently altered during their dissemination. As consequence, a distortion of concepts and procedures persists in history of science. This historical case is an example that to attribute facts, concepts and equations to a historical character implies more than a simple illustration.
\end{abstract}

Keywords: Seebeck effect, Oersted, Historical Experiments.

\section{Introdução}

Um estudo de caso histórico pode levar a diferentes narrativas, de acordo com as perguntas que são postas na pesquisa histórica. Podem ser questionados aspectos metodológicos, conceituais, filosóficos ou socioculturais, permitindo o aprofundamento de um tema restrito (ou seja, um estudo de caso no sentido estrito do termo). Para obter respostas para tais questionamentos, o pesquisador busca por fontes primárias e secundárias, realizando uma análise diacrônica e, preferencialmente, não tendenciosa do tema [1].

Narrativas escritas a partir de estudos de casos históricos considerando tais pressupostos atendem não somente ao que se denomina moderna historiografia da ciência, mas também a propósitos educacionais. É a partir de um estudo restrito, considerando diferentes perspectivas de um tema, que se pode inquirir sobre influências socioculturais e pressupostos epistemológicos. De acordo com propósitos educacionais atuais, a educação em ciências deveria considerar a ciência como um todo, incluindo aspectos sobre o fazer científico, ou sobre a natureza da ciência $[2,3]$.

*Endereço de correspondência: anabispouepb@gmail.com
É nesse sentido que visões distorcidas e histórias anacrônicas da ciência têm sido frequentemente apontadas como desfavoráveis para o Ensino de Ciências. De um modo geral, estes "mal-entendidos" sobre ciências reforçam aspectos positivistas e empíricos-indutivistas que enfatizam uma visão de ciência elitista e neutra. Do ponto de vista historiográfico o whigguismo e as pseudohistórias acabam por enfatizar uma história romanceada que, se não prejudica diretamente o Ensino, também não contribui para uma problematização e questionamentos sobre conceitos científicos e sobre ciência [3,4].

No entanto, em alguns casos estas distorções e malentendidos estão presentes nos trabalhos históricos sob estudo, seja no original ou em obras contemporâneas relacionadas (fontes primárias), conforme exemplifica Martins [5]. Uma leitura desatenta, superficial, ou parcial, de fontes primárias e/ou secundárias, pode perpetuar problemas conceituais e históricos. Quando os estudos de caso envolvem a atividade experimental, distorções tornam-se ainda mais acentuadas. Além de um conhecimento tácito, descrições detalhadas de equipamentos e procedimentos, o trabalho experimental pode envolver ou não um prévio conhecimento teórico [6,7]. Muitas vezes o cientista não descreve o experimento ciente de todo o procedimento que executa ou conhecimento prévio que possui. Ou mesmo, muitas vezes o cientista não 
quer fornecer todos os detalhes do que fez. Diante dessas omissões, conscientes ou não, fontes primárias sobre atividades experimentais às vezes só se tornam claras quando há a tentativa de reproduzir o experimento, o que pode exigir mais do que uma leitura atenta. Como não é possível a reprodução exatamente igual ao original, por diferentes motivos [8], a utilização de procedimentos ou equipamentos anacrônicos também pode levar a uma informação distorcida.

Portanto, o estudo de casos históricos que envolvem um experimento exige uma pesquisa ampla antes da atribuição de fatos, fórmulas, conceitos ou efeitos a determinados personagens da história da ciência. Este artigo detalha um estudo de caso histórico envolvendo experimentação em que a divulgação de resultados feita por um cientista mais conhecido, à época do experimento, acabou levando a uma interpretação totalmente distorcida. Como consequência, não somente o conceito perdeu seu significado no ensino de ciências, como também a atividade experimental envolvida ficou descaracterizada.

O estudo de caso histórico apresentado trata do efeito Seebeck. Atualmente este efeito é descrito como a produção de uma diferença de potencial elétrico na junção de entre dois metais diferentes (condutores ou semicondutores), quando as extremidades da dupla metálica se encontram a diferentes temperaturas entre si (termoeletricidade). É atribuído a Thomas Johann Seebeck, e descoberto em 1821. No entanto, como será discutido, quando Seebeck observou este efeito, associou a diferença de temperatura a um efeito magnético. A relação termoelétrica foi feita por Oersted para fortalecer seu eletromagnetismo, mas não estava de acordo com as ideias de Seebeck.

\section{O ano de 1820}

Em julho de 1820, Hans Christian Oersted (1777-1851) enviou seu trabalho sobre os efeitos do conflito elétrico sobre agulhas magnéticas, escrito originalmente em latim, para sociedades científicas e estudiosos [9]. O experimento de Oersted consistia de um fio ligado a uma bateira galvânica formando um circuito. Quando o circuito era fechado, a agulha de uma bússola localizada sob o fio era defletida. Em seu relato Oersted afirma que o conflito elétrico gerado num condutor, por um aparelho galvânico (pilha), se dispersa circularmente ao redor do fio e afeta as partículas magnéticas da matéria ${ }^{1}$ Ao tomarem conhecimento, vários periódicos científicos europeus publicaram o trabalho, tamanha novidade era sua proposta ao que se discutia sobre a relação entre eletricidade e magnetismo. A relação já era conhecida ${ }^{2}$ mas sua natureza tinha diferentes explicações [10]. O próprio Oersted já havia conjecturado a existência de uma relação entre reações

\footnotetext{
1 Entendemos atualmente este experimento como o campo magnético gerado ao redor do fio sujeito a uma corrente elétrica ("regra da mão direita).

2 Sabia-se, por exemplo, que tempestades afetavam bússolas.
}

químicas, eletricidade, magnetismo, calor e luz, baseada nos princípios da Naturphilosophie ${ }^{3}[11,12,13]$. O que era novo no trabalho de 1820 era a simetria atribuída ao problema, que considerava que havia um movimento transversal (do conflito elétrico) ao fio, ocasionando a deflexão da agulha magnética (efeito magnético) ${ }^{4}[14,15]$. As ideias de Oersted entravam em oposição a outro programa de pesquisa vigente no mesmo momento, baseado nas ideias newtonianas, e que tinha como principais representantes, os franceses como Ampère (1775-1836), Biot (1774-1862) e Savart (1791-1841). De acordo com os franceses, forças centrais, como a eletricidade, são atrativas ou repulsivas e agem linearmente, obedecendo a lei de Coulomb. Para Oersted, as forças elétrica e magnética não eram centrais, e não agiam por atração e repulsão, mas transversalmente [16, p. 378], uma vez que o conflito elétrico era circular em torno do fid ${ }^{5}$. Era importante para Oersted que sua teoria se tornasse reconhecida, o que fez com ele enviasse o trabalho de julho de 1820 para os principais nomes na França, Inglaterra, Alemanha, etc.; e assim que possível, viajasse para divulgá-la pessoalmente.

Na Alemanha desse período havia pelo menos duas interpretações diferentes vigentes entre os estudiosos da eletricidade e do magnetismo. Um grupo de estudiosos tentava fortalecer os aspectos matemáticos dos fenômenos, como é o caso de Ohm (1789-1854) e outros que se destacarão apenas após a década de 1840 [17]. A "velha geração", da qual fizeram parte Ritter (1776-1810), Seebeck (1770-1831), Poggendorf (1796-1877), Schweigger (1779-1857), entre outros, entendiam a matemática como abstrata e manipulável. Apenas o experimento poderia trazer a essência do fenômeno, demonstrando e comprovando o que acontece. Nesse sentido, conforme Caneva [17], a "velha geração" dedicada a eletricidade e magnetismo, está caracterizada pela ausência de resultados quantitativos e falta de explicações detalhadas sobre os dados experimentais. Para esses experimentadores, uma série de repetições, alterando as variáveis, permitia adquirir um conhecimento geral sobre o que estava acontecendo e, daí compará-lo com algo já conhecido, por analogia. Ainda entre os membros da "velha geração", alguns adotavam a polaridade da natureza (Naturphi-

\footnotetext{
3 A Naturphilosophie pressupunha que na natureza havia uma força central, da qual todas as outras derivavam. As forças derivadas eram sempre polares, de forma a manter um equilíbrio e se conservarem. O conceito de força na Naturphilosophie é muito semelhante ao que entendemos atualmente como energia e as ideias de conservação e polaridade são complexas. Para entender melhor a Naturphilosophie, sugerimos a leitura de Caneva [11] e Silva e Silva [12].

${ }^{4}$ Há várias referências que discutem o trabalho de 1820 de Oersted e seu significado. Sugerimos Martins [5,14] e Gardelli [15].

$5 \mathrm{O}$ conceito de conflito elétrico está relacionado à natureza da eletricidade. No século 19 havia várias explicações para o que seria a eletricidade. Poderia ser um fluido em excesso ou em falta, ou então dois fluidos contrários. Para Oersted, considerando a polaridade presente na Naturphilosophie, a eletricidade era constituída de dois fluidos (positivo e negativo) movimentando-se no interior do fio $[10]$.
} 
losophie) como principal forma de explicar fenômenos. Mesmo entre os Naturphilosophen (filósofos que adotavam a Naturphilosophie) da "velha geração" havia diferentes interpretações, principalmente no que diz respeito a importância do experimento para adquirir conhecimento $[12,17]$.

Quando o trabalho de Oersted se tornou conhecido, muitos estudiosos tentaram replicá-lo, buscando confirmar suas observações ${ }^{6}$ Para que a réplica fornecesse os mesmos resultados, era necessário que o circuito possuísse pequena resistência, o que nem todos sabiam à época. Confirmadas as observações, tentaram construir instrumentos que intensificassem o efeito magnético sobre a bússola, já que no experimento original a deflexão da bússola era muito pequena. Estes instrumentos ficaram conhecidos como multiplicadores e, de um modo geral, envolviam várias voltas de um fio de cobre formando espiras, com as extremidades livres para conectar à bateria. As voltas podiam ser sobrepostas ou paralelas, verticais ou horizontais, e no seu centro ficava a bússola ${ }^{7}[17,18]$. Para estes instrumentos, diferentes variáveis influenciavam no resultado final, e muitas ainda não eram conhecidas e, portanto, não era possível saber como afetavam a intensidade e a direção do magnetismo ao redor do fio. Por exemplo: a espessura e formato do condutor, o número de voltas, o sentido da volta (horário ou anti-horário), etc.; e pelo menos três estudiosos apresentaram instrumentos diferentes como uma possível solução para multiplicar o efeito magnético sobre a bússola. Poggendorf, Schweigger e Cumming (1771-1861), independentemente um do outro, apresentaram modelos de multiplicadores em 1821, sendo os dois primeiros em alemão e o último em inglês [19]. Em seus trabalhos, nenhum dos três é muito preciso em relação às especificidades do material, dos procedimentos e do instrumento. Também não tinham muita clareza de porquê havia a multiplicação, já que isso implicava em aceitar a teoria de Oersted (efeito magnético transversal ao fio) ou o modelo francês (atração linear). Para Chipman [19], o multiplicador apresentado por Schweigger é o menos real dos três, pois suas hipóteses são inapropriadas e não há considerações sobre a influência dos polos do meridiano magnético no instrumento.

Entretanto, essa não foi a opinião de Oersted, ao divulgar o multiplicador de Schweigger.

Imediatamente após a descoberta do eletromagnetismo, prof. Schweigger, de Halle, inventou instrumento extremamente útil com o objetivo de descobrir correntes elétricas muito fracas por meio de agulhas magnéticas. O efeito deste multiplicador está fundamentado sobre a igualdade da ação que cada parte de um fio condutor exerce sobre a agulha mag-

\footnotetext{
6 O experimento de Oersted consistia apenas de um aparelho galvânico ligado a um fio, formando um circuito fechado. Sob o fio, havia uma bússola. O experimento está detalhado em Martins [10].

7 Sobre multiplicadores sugerimos Cavicchi [18] e Chipman [19].
}

nética quando ele transmite uma corrente [20].

Na sequência, Oersted ainda comenta sobre o multiplicador criado por Poggendorf logo após Schweigger e os experimentos que ele realizou, considerando o mesmo fenômeno. As referências às datas de apresentação dos instrumentos e dos experimentos, e as respectivas publicações divulgando, não deixam claro se há uma primazia entre Poggendorf e Schweigger. Mas o fato de Oersted ter colocado sua atenção na explicação do multiplicador de Schweigger, pode ser uma das causas para este instrumento ser o mais popular entre os demais estudiosos do período.

Utilizando-se do multiplicador, experimentos com diferentes configurações foram realizados para tentar entender melhor a natureza da relação entre eletricidade e magnetismo que Oersted estava divulgando. Entre novembro de 1822 e agosto de 1823, Oersted realizou uma viagem por várias cidades da Europa, incluindo Inglaterra, divulgando sua teoria e conhecendo os trabalhos que estavam sendo feitos baseados nela [16, p. 99; 21, p. $10]$.

\section{O efeito "termoelétrico"}

Thomas Johann Seebeck (1777-1831) foi um dos estudiosos que Oersted visitou em Berlim. Seebeck havia assumido uma posição na Academia de Berlim em 1819, após ter morado em diferentes cidades da Alemanha, como Jena, Bayreuth e Nuremberg. Em Jena, conheceu a Naturphilosophie e iniciou amizades duradouras com Goethe (1749-1832) e Weiss (1780-1856). Pouco se sabe sobre sua vida pessoal, além da correspondência trocada com Goethe, a qual se reduziu drasticamente após sua entrada na Academia [22].

Entre 1806 e 1820, os trabalhos de Seebeck trataram de propriedades de minerais e metais, reações químicas, polarização da luz e magnetismo. Entre 1806 e 1827 (último artigo publicado), Seebeck não tem mais que 10 artigos e algumas notas em jornais científicos da época $[22 ; 23, \text { p. } 620]^{8}$

\subsection{Eletricidade e magnetismo}

Após tomar conhecimento do trabalho de Oersted, Seebeck iniciou uma série de experimentos sobre magnetismo. O primeiro trabalho foi apresentado na Academia em dezembro de 1820, mas publicado por completo apenas em 1822 [24]. Neste trabalho, Seebeck procura questionar se a única condição para a excitação magnética é a variação contínua da tensão elétrica e onde isso ocorre. Quais

\footnotetext{
8 No Catalogue, para o período entre 1806 e 1827, Seebeck possui 18 trabalhos, entre artigos e notas, a maioria em alemão. Comparativamente, no mesmo período, Oersted possui 60 trabalhos, entre artigos e notas, em dinamarquês, alemão, inglês e francês. Apenas o trabalho de 1820 foi em latim. Isto mostra claramente que, na época, Oersted já era conhecido pelos acadêmicos em vários países.
} 


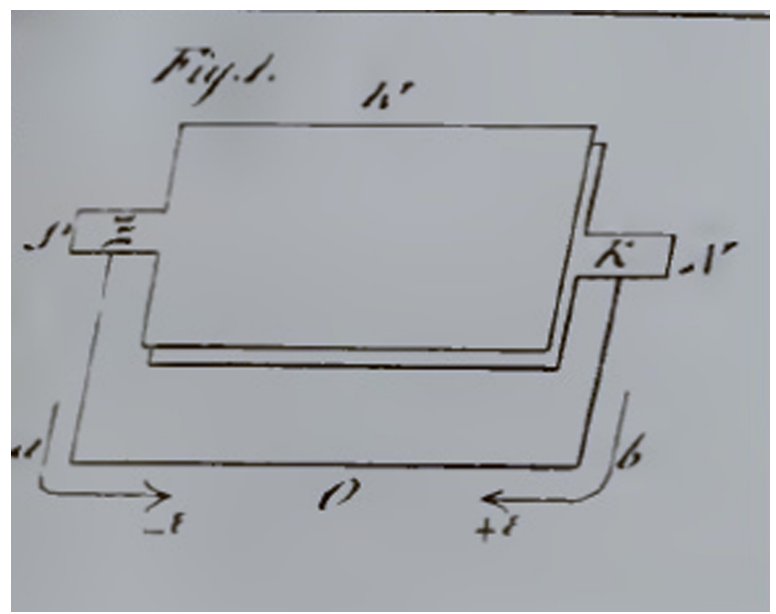

Figura 1: Circuito montado por Seebeck para identificar a polaridade magnética. A placa de cobre $(K)$ se encontra embaixo e a de Zinco (Z) acima. N aponta para o norte magnético. Ao longo do fio de cobre que conecta as duas placas, $b$ aponta a direção da eletricidade $+\mathrm{E}$, e $d$ aponta da eletricidade - E. Fonte: Seebeck [24].

seriam as condições necessárias para produzir outras tensões magnéticas nos corpos? Ele inicia reproduzindo os experimentos de Oersted usando um par de cobre e zinco, ligados de acordo com a figura 1. As duas placas têm entre si uma solução para condução, feita de ácido sulfúrico diluído em água e sal. De uma extremidade a outra de cada placa sai um fio de cobre que fica paralelo ao plano das placas. Esse conjunto (placas mais fio) é colocado em diferentes posições em relação a bússola. Realizando uma série de combinações de posições relativas do fio (corrente) com a bússola, Seebeck encontra as mesmas inclinações e declinações obtidas por Oersted. Conclui:

Estes experimentos provam que existe uma polarização magnética peculiar na corrente galvânica fechada, independente de todas as influências externas, e que a mesma é invariável ao se inverter a posição dos polos elétricos da corrente [24, p. 293].

Seebeck denominou a tensão magnética pelas polaridades magnéticas $+\mathrm{m}$ e $-\mathrm{m}$, numa analogia com as polaridades elétricas $+\mathrm{E}$ e $-\mathrm{E}$. Ele não deixa explícito qual conceito de fluido elétrico está utilizando, mas assumir a polaridade pode significar que considere dois fluidos. Já o conceito de tensão magnética se aproxima da ideia moderna de campo, mas não esclarece as causas da configuração circular em torno do fio [22]. Partindo da compreensão de que a polarização magnética depende apenas da corrente galvânica fechada, Seebeck buscou entender quais as variáveis que influenciavam a intensidade da deflexão da agulha magnética (ângulo). Para isso, ele utilizou duas bússolas, dispostas no interior de dois fios de cobre (A e B), associadas à bateria voltaica (Fig. 2), como se fossem dois circuitos ligados à mesma bateria. Dependendo do comprimento de A e B, eles eram

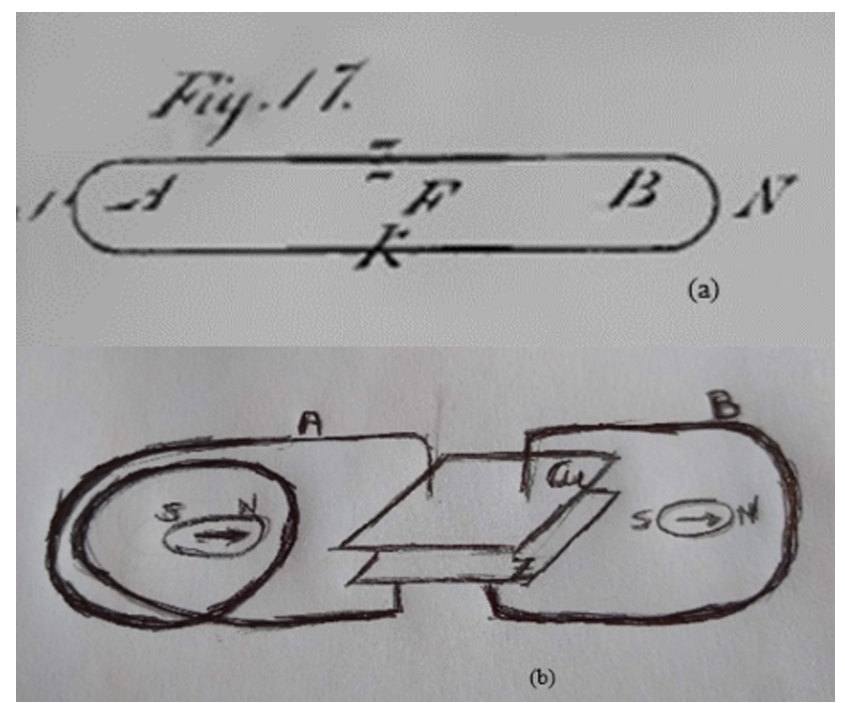

Figura 2: (a) Desenho original de Seebeck. Fonte: Seebeck [24]. (b) Representação do circuito de acordo com a descrição e o desenho de Seebeck. $Z$ e Cu representam as placas de zinco e cobre que constituem a bateria voltaica. $A$ e $B$ são fios de cobre. No interior de $A$ e $B$ há uma bússola. $\mathrm{N}$ é o norte magnético terrestre. Fonte: a autora.

enrolados formando várias espiras, e a bússola ficava no centro da espira.

Ele variou: o material, o comprimento, a largura e a espessura dos fios em A e B 9 , que formavam espiras, fez medidas em cada espira isoladamente e depois com as espiras emendadas, e modificou a solução condutora no interior da bateria voltaica (apenas água, ou água+sal+ácido sulfúrico). Observou que a configuração da polarização magnética (Fig. 3) permanecia a mesma (circular, transversal ao fio), mas que a tensão magnética era inversamente proporcional ao comprimento do fio, sendo que, em alguns casos, a deflexão magnética diminuía após um certo tempo, mas não havia uma variação desta deflexão em função da solução usada na bateria voltaica. Assim, ele atribuiu essa diminuição a uma variação da temperatura. Sem explicar detalhadamente a que procedimento ou limite de temperatura está se referindo, Seebeck menciona em nota de rodapé:

No entanto, nem todo aumento na temperatura do condutor que fecha a corrente galvânica causa um aumento do estresse magnético. Abaixo das hastes de metal, que eram colocadas brilhando nos suportes presos a uma corrente simples, o desvio da agulha magnética não era grande, mas não menor do que quando as hastes estavam frias. No entanto,

\footnotetext{
9 Quando o comprimento do fio em A e B era grande, Seebeck enrolava-o circularmente, como uma espira. Na experiência 17 (Fig. 2), ele usa um "multiplicador de Schweigger" em B. De acordo com a descrição de Seebeck, este multiplicador consistia de 12 metros de uma fita de cobre de $0,5 \mathrm{~cm}$ de largura, enroladas na forma de espiras, com as camadas isoladas por seda; e em A usa uma faixa de cobre de mesma largura $(0,5 \mathrm{~cm})$ e $45,8 \mathrm{~cm}$ de comprimento.
} 


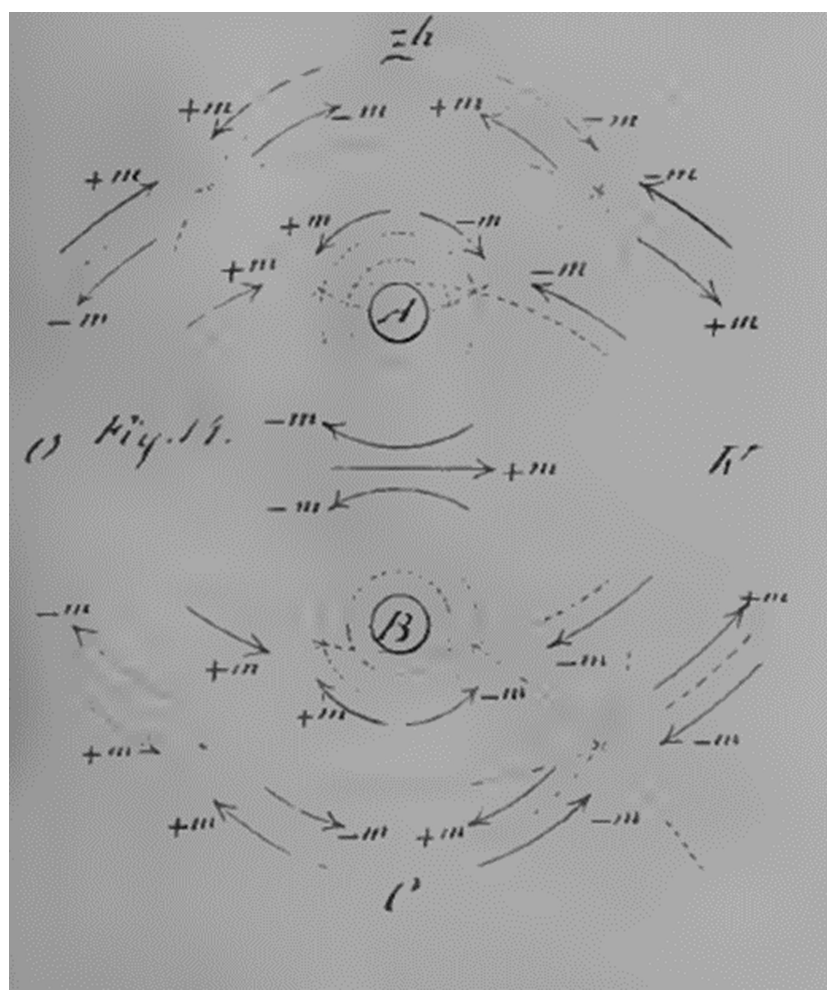

Figura 3: Corte transversal do circuito representado na Fig. 2. AeBrepresentam os fios de cobre. Dispondo a bússola em diferentes posições em relação a $A$ e $B$, Seebeck determina a polaridade magnética $+\mathrm{m}$ e $-\mathrm{m}$ em relação à eletricidade nas espiras. Observa-se que a configuração da polaridade magnética em torno dos fios é circular. Fonte: Seebeck [24].

o sucesso teria sido diferente se as hastes incandescentes tivessem acabado de tocar as placas de metal, como o ensaio a seguir mostrará com mais clareza [24, p. 325 - nota de rodapé].

A partir da afirmação de Seebeck, pode-se supor que o experimentador fundia as terminações das espiras às partes superior e inferior da bateria voltaica para formar o circuito. Para que a temperatura fizesse diferença na deflexão da agulha, era necessário que a extremidade da espira a ser fundida estivesse incandescente, não apenas quente, no contato com o a placa metálica da pilha. Após a espira entrar em equilíbrio térmico com a bateria voltaica, a deflexão começava a diminuir. Esta é uma das conclusões que podem tê-lo levado a investigar a relação entre magnetismo e diferença de temperatura no próximo trabalho que será tratado aqui.

Ainda com relação à eletricidade e magnetismo no trabalho de 1822, Seebeck argumenta que ao fechar o circuito, as polaridades elétricas $+\mathrm{E}$ e $-\mathrm{E}$ se anulam e, portanto, é esse cancelamento que provoca mudanças internas no metal, gerando a tensão magnética. Ele ainda afirma que, se a eletricidade fosse a causa do magnetismo, então a bateria voltaica onde ocorre a reação química também deveria ter magnetismo, o que não é o caso
[24, p. 332]. Portanto, ele é levado a concluir que o que causa a polarização magnética é uma modificação interna no metal, como aquecimento, derretimento, etc., com a remoção da tensão elétrica.

A mudança ou dissimilaridade no estado de coesão deve, portanto, ser considerada como a condição mais essencial para a magnetização desses corpos [22, p. 334].

\subsection{Magnetismo e calor}

Ainda que não estejam claros os argumentos para assumir essa posição, Seebeck considera que não é a eletricidade em si que causa a polarização magnética no circuito como um todo. Como as eletricidades $+\mathrm{E}$ e $-\mathrm{E}$ se anulavam no interior da bateria voltaica quando circuito era fechado, não era o conflito elétrico que provocava o efeito magnético observado pela deflexão da bússola. Neste sentido, ele está em desacordo com a teoria de Oersted, a qual mencionava que o conflito elétrico se estendia ao redor do fio, alterando as propriedades magnéticas da matéria 10 . Seebeck concorda com a configuração da polarização magnética transversal ao fio, mas o que a causa não é o conflito elétrico. Para Seebeck, a diferença de temperatura não influencia nas polaridades elétricas e, portanto, não há uma relação entre calor-eletricidade-magnetismo. Apenas calor-magnetismo.

Antes de analisarmos o trabalho de Seebeck, é necessário fazer uma ressalva quanto às datas. Os experimentos realizados em 1820 foram publicados num volume dos Anais da Academia de Berlim (Abhadlungen der physikalischen Klasse der Königlisch-Preußsischen) de 1822, contendo trabalhos dos anos de 1820 e 1821. Seebeck deu andamento aos seus experimentos ainda em 1821, apresentando-os diante da Academia em quatro palestras entre agosto de 1821 e fevereiro de 1822. Mas o trabalho completo só foi publicado nos Anais da Academia em 1825, num volume contendo trabalhos dos anos $1822 \mathrm{e}$ 1823. Na versão publicada, Seebeck adiciona ideias posteriores às datas dos seus experimentos, informando seu leitor em notas de rodap ${ }^{11}$.

Dando continuidade ao trabalho envolvendo magnetismo, Seebeck irá realizar uma série de experiências para investigar melhor fenômenos que, segundo ele, "me pareciam indicar que dois metais, conectados em círculo uns com os outros, eram magnéticos sem a participação de nenhum condutor úmido" [25, p. 4].

No primeiro experimento que faz utiliza o multiplicador de Schweigger mencionado na Fig. 2 (nota de rodapé), um disco de cobre e um disco de bismuto. Ele não descreve o tamanho da bússola, nem as espessuras da fita de cobre ou dos discos utilizados. Conforme Figura 4, sobre a extremidade inferior da fita de cobre (multiplicador), estavam o disco de cobre e, sobre ele, o disco de bismuto.

10 Conforme consta na seção 1 deste artigo.

11 A versão utilizada aqui é a de 1825 e uma reedição de 1895 [25] com notas do organizador. 


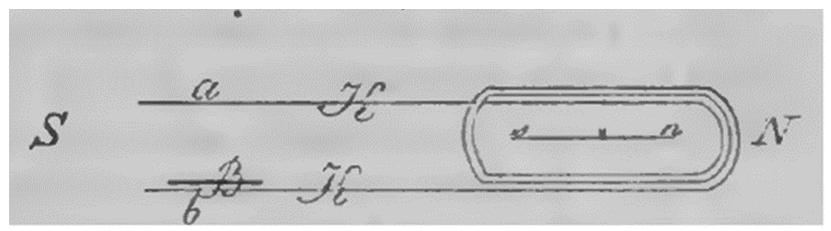

Figura 4: Primeiro experimento de Seebeck para investigar a relação entre calor e magnetismo. A espira (multiplicador de Schweigger) é de cobre $(K)$. Ao final da espira ficam em contato um disco de cobre, bismuto (B) e a extremidade superior da espira. No interior da espira está uma bússola. Fonte: Seebeck [26]

Segundo Seebeck $[25$, p. $5 ; 26]$, ao pressionar com seu dedo a parte superior da fita de cobre sobre o disco de bismuto, a bússola sofre uma deflexão para oest $\AA^{12}[27]$.

Como a deflexão poderia estar associada a uma reação química entre os metais, usando a umidade da mão como condutora, Seebeck utiliza diferentes materiais para pressionar o conjunto cobre-bismuto-cobre. Ele usa madeira, outro metal e um papel umedecido. Em nenhum desses casos a deflexão ocorre. Usando novamente a mão, Seebeck verifica se a deflexão pode ocorrer com outros metais diferentes do bismuto. Ele substituiu o disco de bismuto por um de antimônio e obteve um desvio a leste. Outros metais como níquel, cobalto e urânio se comportaram como o bismuto; ferro, arsênio e telúrio, como o antimônio. Mas com um disco de zinco ou de prata, por exemplo, não houve deflexão.

A ausência de deflexão com o zinco eliminava a possibilidade de uma reação galvânica. A ausência de deflexão quando a mão é substituída por outros materiais eliminava a possibilidade de um fenômeno apenas mecânico. Como a tensão magnética deveria vir de uma mudança no "estado de coesão do metal", conforme resultados do trabalho anterior, Seebeck concluiu que era o calor transferido pela mão que causava o magnetismo $[25, \mathrm{p}$. 9].

Para averiguar se suas conclusões estavam corretas, Seebeck adotou uma outra configuração de experimentos (Fig. 5), em que a temperatura poderia ser aumentada e, esperava-se, a deflexão fosse ainda maior.

No experimento da Fig. 5, Seebeck coloca uma barra de bismuto de $10 \mathrm{~cm}$ entre as extremidades do multiplicador de Schweigger (feito com os 12 metros de fita de cobre enroladas na forma de espira), e aquece a extremidade inferior com uma vela. A deflexão da agulha magnética é para oeste, com maior intensidade do que quando o circuito foi fechado apenas com a mão. Ele substitui o bismuto por barras de outros metais, como antimônio, níquel, ouro, etc., e a espira de cobre por espiras de outros metais, como níquel, cobalto, etc. Usando como parâmetro a deflexão para oeste $(\mathrm{W})$ ou leste $(\mathrm{O})$, Seebeck construiu uma tabela, muito semelhante ao que já se

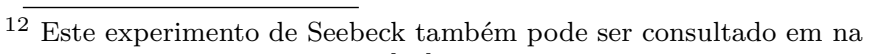
tradução de Ferreira e Silva [27].

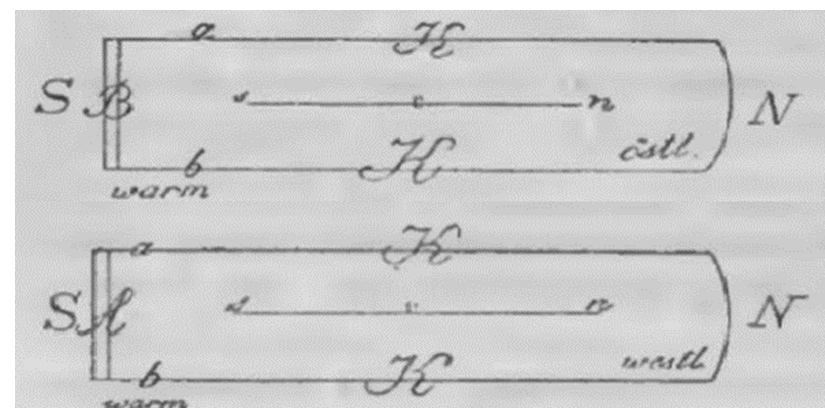

Figura 5: Experimentos com uma espira de cobre e uma barra de bismuto (acima) ou Antimônio (abaixo). Na extremidade inferior (b warm) as barras são aquecidas com uma vela. Fonte: Seebeck [26].

conhecia sobre eletricidade estática ${ }^{13}$ indicando qual seria a direção da deflexão para diferentes combinações metálicas (Fig. 6).

Ele verificou que não era o calor que provocava a deflexão da agulha, mas uma diferença de temperatura entre os pontos de contato das combinações metálicas. Quando as duas extremidades estavam a mesma temperatura, seja por aquecimento ou por resfriamento; ou quando a barra era aquecida no meio, havia a modificação na "coesão do metal", mas o magnetismo permanecia latente. Apenas com a diferença de temperatura entre as extremidades é que se produzia tensão magnética. Seebeck conclui:

De todos esses experimentos podemos concluir que a primeira e mais importante condição para o aparecimento do magnetismo livre nesse circuito metálico é a diferença de temperatura nos pontos de contato dos dois elementos. Sem dúvidas o magnetismo também será provocado se ambos os pontos de contato dos metais ou minérios são aquecidos

\begin{tabular}{|c|c|c|c|c|c|c|c|c|c|c|c|}
\hline Gold Nr. $1 \ldots$ & 0 & 0 & 0 & c & 0 & 0 & & $\geqslant$ & $\geqslant 1$ & $\geqslant$ & \\
\hline Uran ...... & 0 & 0 & & & 0 & & $\geqslant$ & $\geqslant$ & $\equiv$ & & \\
\hline Platina Nr. $1 .$. & 0 & 0 & 0 & o & & $\geqslant$ & $\geqslant$ & $\geqslant$ & $\geqslant$ & $\geqslant$ & \\
\hline Palladium ... & 0 & 0 & & & 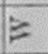 & & $\geqslant$ & $\geq$ & $\geqslant$ & & \\
\hline Kobalt . . . . & 0 & 0 & & & $=$ & & $\Rightarrow$ & $\equiv$ & 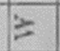 & & \\
\hline Nickel . . . . . & 0 & & $=$ & 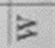 & $\geqslant$ & $\geqslant$ & $\geqslant$ & $\geqslant$ & $\geqslant$ & $\geqslant$ & \\
\hline Wismuth... & & $\geqslant$ & $\geqslant$ & $\geqslant$ & 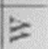 & $\geqslant$ & $\geqslant$ & 3 & $\geqslant$ & $\geqslant$ & $=$ \\
\hline In Norden. & $\frac{\vec{*}}{3}$ & 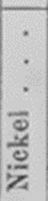 & : & 竞 & 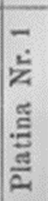 & 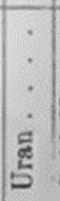 & : & 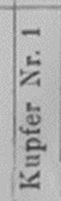 & 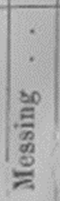 & 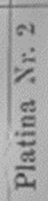 & 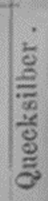 \\
\hline
\end{tabular}

Figura 6: Tabela associando a direção de deflexão da bússola de acordo com as duplas de metais em contato, a diferentes temperaturas. Fonte: Seebeck [26]

13 Uma tabela indicando atração e a repulsão de diferentes materiais. 
ao mesmo tempo e a um mesmo grau; não haverá nenhuma ação na agulha magnética, no entanto, neste caso, porque através deste procedimento uma dupla e oposta polarização magnética será provocada no circuito, e é em toda parte de igual força [25, p. 11].

Seebeck então fez circuitos termomagnéticos utilizando barras de diferentes comprimentos para verificar como se dava a variação da intensidade da deflexão de acordo com o comprimento (Fig. 7). Para isso, ele conectou barras de cobre e de bismuto e antimônio, variou as temperaturas nas extremidades onde havia contato entre os metais e verificou a deflexão da bússola [25, p. 15]. Com os resultados, ele fez uma nova tabela reordenando as combinações de metais como "mais a oeste" ou "mais a leste", de forma totalmente fenomenológica.

Seebeck ainda tentou circuitos circulares e arriscou um modelo teórico para explicar "estados de magnetização", $+\mathrm{m}$ ou $-\mathrm{m}$, em um único metal. Ele conjecturou que um único metal, com uma das extremidades aquecida previamente, quando fechado em forma de anel, também ficaria magnetizado [25, p. 72]. Porém, sua argumentação é bem confusa e não chega a uma conclusão final [22].

De forma totalmente qualitativa e fenomenológica, Seebeck conclui que: (i) deve haver uma diferença de temperatura entre os pontos de contato para que haja tensão magnética; (ii) a intensidade da tensão magnética no circuito termomagnético é proporcional à diferença de temperatura; (iii) a configuração do magnetismo em circuitos termomagnéticos é a mesma que em circuitos elétricos e; (iv) a intensidade da tensão magnética é inversamente proporcional ao comprimento dos condutores [22, 25]. Com exceção de alguns resultados iniciais (primeiro ex-

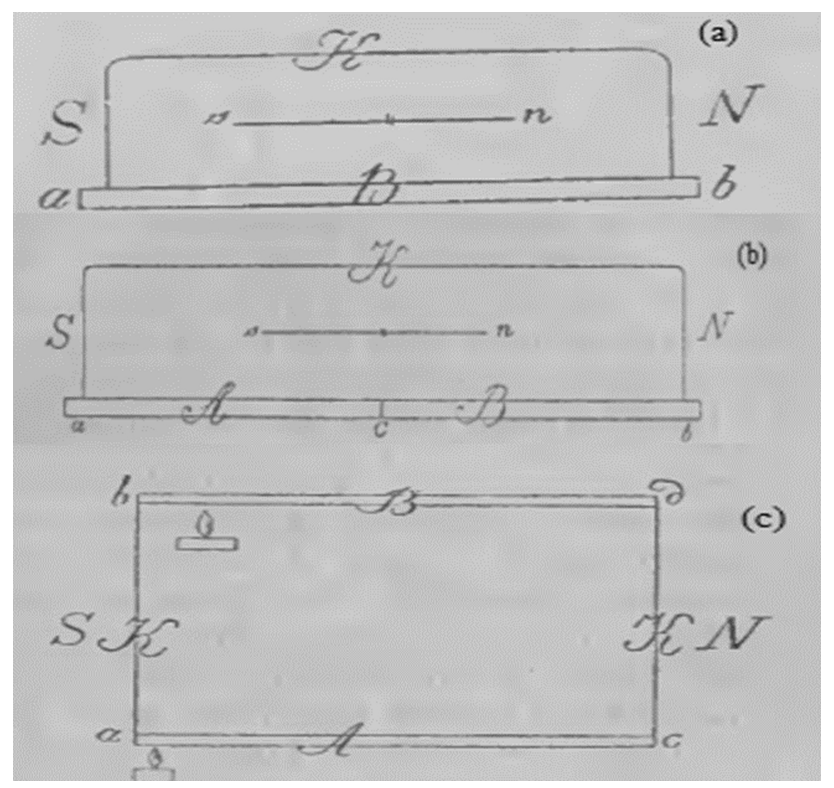

Figura 7: Circuitos termomagnéticos: (a) bismuto-cobre; (b) antimônio-bismuto (em série) -cobre; (c) antimônio-bismuto (em paralelo) -cobre. Fonte: Seebeck [24]. perimento), Seebeck não fornece os valores de deflexão da bússola (ângulo), nem valores para as temperaturas. Ele também menciona que o aquecimento e resfriamento dos metais poderia alterar sua estrutura interna e causar modificações na magnetização, mas não esclarece de que forma isso ocorreria [25, p. 78].

Ao final do trabalho, Seebeck apresenta considerações sobre como o presente estudo poderia servir para explicar o magnetismo terrestre, uma vez que se supunha que o interior da Terra possuía muitos metais sujeitos a diferentes temperaturas devido à posição em relação ao Sol [25, p. 112].

\subsection{Sobre as conclusões de Seebeck}

A análise do trabalho de Seebeck mostra, claramente, de que se trata de um estudioso influenciado pelas ideias românticas da Naturphilosophie. Ele ressalta a existência de polaridades e de uma relação entre as diferentes forças da natureza, como calor, eletricidade, reação química, magnetismo ${ }^{15}$ A polaridade está presente nos estados de magnetização, assemelhando-se aos estados de eletrização e também à polarização da luz, na qual Seebeck já havia desenvolvido trabalhos anteriormente [22]. Nesse sentido, ele se aproxima bastante das ideias de Oersted, que também era um entusiasta da Naturphilosophie e da organicidade da natureza, com todas as forças se relacionando. Porém, Seebeck não menciona em nenhum dos seus experimentos que é a eletricidade produzindo o efeito magnético. De acordo com o que ele mesmo havia discutido no trabalho anterior, a eletricidade mantinha-se encerrada na bateria voltaica. Como os presentes experimentos não utilizam uma bateria voltaica, não há presença, para Seebeck, de eletricidade no circuito termomagnético.

Seebeck também é um exemplo de como se dava a experimentação entre os filósofos naturais do início do século 19, pelo menos na Alemanha: qualitativa e restrita em termos de descrição de materiais, instrumentos, procedimentos e acuidade. Trata-se de uma experimentação exploratória, conforme Steinle [6] argumenta, mas ainda sem uma sistematização bem justificada. Seebeck iniciou com a investigação de um fenômeno básico fazendo uma longa série de experimentos qualitativos. Na sequência, ele tornou os experimentos mais complexos, criando os circuitos com pares bimetálicos, mas não obteve novos resultados. Depois ele tentou uma análise teórica (os "estados de magnetização") a partir da ideia mais simples, que era produzir magnetismo num anel do mesmo metal, apenas aquecendo- $\mathrm{d}^{16}$

\footnotetext{
14 Para Seebeck, os vulcões também influenciariam na diferença de temperatura entre os diferentes metais e, consequentemente, no magnetismo terrestre. Suas conjecturas seguem as ideias de Humbolt sobre o magnetismo terrestre.

15 Vide nota de rodapé 3.

16 Para Nielsen [22], este método é uma influência direta da forma como Goethe associava experimentos e teoria.
} 
Mesmo tratando-se de uma forma comum de estudos experimentais no início do século 19, alguns procedimentos de Seebeck são insatisfatórios e deveriam, à época, terem sido testados e contestados. Por exemplo, na conclusão (i), não está claro a que diferença de temperatura Seebeck se refere. Ele não informa a temperatura ambiente, nem a que temperatura a deflexão é maior. Nem mesmo descreve se há um termômetro. Uma tentativa inicial de reprodução do experimento de Seebeck 17 aponta que seu argumento inicial (é a temperatura da mão que provoca a tensão magnética), depende de outras variáveis, como: temperatura ambiente, temperatura do corpo humano, região de contato, espessura dos discos e da fita de cobre ${ }^{18}$ [28]. Se este argumento não é válido, já que a diferença de temperatura ambiente em relação ao corpo humano não é grande o bastante para produzir a magnetização, o que o levou a conduzir os demais experimentos e desprezar as outras hipóteses? Provavelmente já havia uma tendência a considerar que deveria haver uma relação entre calor e magnetismo, como pressupunha a Naturphilosophie.

Trabalhando com metais de pontos de fusão tão distintos (bismuto a $270{ }^{\circ} \mathrm{C}$ e cobre a $1085^{\circ} \mathrm{C}$ ), qual é o limite de temperatura de aquecimento que permite concluir (ii)? Seebeck não menciona os valores de temperaturas, nem de que forma está fazendo as junções, o que poderia alterar seus resultado\$ 19 Se os metais são fundidos com uma solda a base de cobre, isso implicaria em já fundir o bismuto também, alterando sua estrutura interna. Ele chega a apontar, em nota de rodapé, que pesquisas posteriore ${ }^{20}$ de Cumming mostraram que há um limite, mas não se aprofunda [25, p. 94].

Na conclusão (iii) fica evidente de que ele concorda com Oersted no que concerne aos ideais românticos, opondose ao modelo francês de atração e repulsão, e assumindo que as forças são transversais. Mas discorda quanto à existência de uma corrente elétrica produzindo os efeitos magnéticos. No entanto, Seebeck não menciona qual o sentido adotado ao enrolar na construção da espira (multiplicador). O sentido da espira vai influenciar na direção que a agulha deflete quando há a diferença de temperatura. Portanto, a tabela de comparação "leste-oeste" pode estar totalmente invertida. Além disso, aquecendose outra parte do circuito, a direção inverte. Por exemplo, na Fig. 4, se o aquecimento for feito no disco de cobre abaixo do disco do bismuto, a deflexão é para o leste. Esta contradição poderia ter sido apontada à época, invalidando os resultados de Seebeck.

No entanto, não foram encontradas críticas posteriores aos procedimentos de Seebeck, nem sequer quanto aos

\footnotetext{
17 A ser detalhada em outro trabalho.

18 Seebeck menciona que o multiplicador de Schweigger que está usando possui 12 metros de uma fita de cobre de $0,5 \mathrm{~cm}$ de largura, mas não informa qual é a espessura da fita.

19 Os limites de temperatura serão estudados posteriormente por Becquerel, usando o aquecimento com mercúrio [28, p. 575].

20 Este é um exemplo das adições que Seebeck fez ao seu relato para a publicação em 1825 .
}

resultados a que ele chegou. Pelo contrário, até mesmo suas considerações sobre uma possível explicação para o magnetismo terrestre a partir do termomagnetismo foram utilizadas como plausíveis [29]. Isto nos leva a concluir que o próprio contexto permitia tantas imprecisões experimentais e resultados apenas fenomenológicos. Por outro lado, somos levados a questionar: se Seebeck argumentou que a diferença de calor provoca um efeito magnético termomagnetismo - por que é adotado atualmente como termoelétrico, ou seja, a diferença de calor provoca um efeito elétrico (potencial elétrico)? Afinal, Seebeck deixou bem claro que não há contribuição da eletricidade na polarização magnética, e nem havia um instrumento que media ou produzia diretamente eletricidade nos experimentos que ele fez. A resposta dessa última pergunta está no interesse que Oersted teve nos experimentos de Seebeck.

\section{A versão de Oersted}

Em 04 de abril de 1823, Oersted escreveu a sua esposa:

Como escrevi alguns dias atrás, fiz uma interessante descoberta, a saber, de um aparato galvânico que consiste somente de materiais sólidos sem a mediação de qualquer líquido.(...) Com a ajuda da minhas descobertas eletromagnéticas, Seebeck em Berlim chegou a mais bonita das descobertas que surgiu da minha, especificamente que se alguém monta um anel de dois pedaços curvos feitos de diferentes metais e aquece uma das junções, o anel inteiro tem o mesmo efeito sobre a agulha da bússola como um circuito galvânico. Os dois metais que fornecem melhor efeito neste experimento são o bismuto e o antimônio. Um pedaço destes dois metais soldados juntos tem o mesmo efeito que zinco e cobre num circuito galvânico. E eu ouso dizer que, desta forma, o calor tem o efeito do líquido [21, p. 340].

Na apresentação do trabalho de Seebeck na Academia de Ciências de Paris em 1823 [30], p. 462], Oersted salienta a necessidade de distinguir entre um circuito termoelétrico de um circuito hidroelétrico (galvânico). Segundo ele, num circuito termoelétrico como o de Seebeck,

Se o circuito é composto de cobre e bismuto, a eletricidade positiva se move do cobre para o bismuto na parte que ainda não foi aquecida, mas se o circuito é composto de cobre e antimônio, a direção da corrente é do antimônio para a parte não aquecida do cobre [30, p. 462].

Ou seja, Oersted está associando a direção de deflexão da agulha (oeste-leste) dada por Seebeck, ao sentido da 
eletricidade no circuito. Juntamente com Fourier, Oersted realizou alguns experimentos baseados na termoeletricidade [30, p. 470-477]. De forma mais detalhada e sistemática que Seebeck, eles descrevem os circuitos feitos de antimônio e bismuto. Variando o número de barras e junções nos circuitos, Oersted e Fourier pretendem examinar qual o limite de elementos para que o efeito termoelétrico seja máximo.

Eles começam com um circuito hexagonal formado por 3 barras de bismuto e 3 barras de antimônio, de $12 \mathrm{~cm}$ de comprimento, $15 \mathrm{~mm}$ de largura e $4 \mathrm{~mm}$ de espessura cada. Aquecem ou resfriam um ou mais pontos de junção e observam o ângulo de deflexão da agulha da bússola localizada no centro do circuito. As observações são feitas também para circuitos formados por mais elementos até o máximo de 22 barras de cada um dos metais (Fig. 8). Comparando os ângulos obtidos, eles concluem que efeitos magnéticos mais fortes ocorrem com elementos mais curtos (quarta conclusão de Seebeck), o que dificultaria manter as diferenças de temperatura, uma vez que o equilíbrio térmico seria facilmente atingido.

Mesmo adotando um procedimento mais sistemático, Oersted e Fourier não fornecem vários detalhes das configurações que sabemos, atualmente, influenciam nos resultados, como: de que forma as barras são unidas, as temperaturas ambiente e de aquecimento, a distância entre a bússola e as barras, etc. Assim como em Seebeck, os esboços apresentados também não colaboram para uma melhor compreensão dos experimentos. Os experimentos ainda são, nesse momento, qualitativos e fenomenológicos. Não há uma expressão matemática que relacione o ângulo de deflexão à intensidade da eletricidade e os experimentadores não estão em busca disso. Não se trata de uma metodologia errada, mas de uma forma de procedimento experimental característica da primeira metade do século 19.

Em todos os circuitos montados, Oersted e Fourier se referem ao efeito termoelétrico. A bússola, nestes casos, não está lá para determinar o efeito magnético, mas para, indiretamente, identificar a intensidade do efeito elétrico produzido pela diferença de temperatura. $\mathrm{Ou}$ seja, eles estão assumindo que a teoria eletromagnética de Oersted é válida e há uma relação entre eletromagnetismo e calor. Seebeck não menciona eletromagnetismo em seus experimentos. Para Seebeck há uma relação entre magnetismo e calor, sem a presença de efeitos elétricos.

A associação entre eletromagnetismo e calor aparece também no verbete sobre termoeletricidade que Oersted escreve em 1830 para The Edinburgh Encyclopadia

Termo-eletricidade é um termo introduzido em filosofia natural alguns anos atrás, para significar a corrente elétrica, excitada em um circuito de condutores quando o equilíbrio do seu calor é perturbado de tal maneira que causa alí uma circulação de calórico. Termoeletricidade sendo um braço particular do Eletromagnetismo, que foi descoberto desde a publicação do trabalho em que foi tratado, será necessário compreender toda a doutrina do eletromagnetismo no presente verbete $[28$, p. 542, itálico no original].

No restante do verbete, Oersted descreve a sua teoria eletromagnética, desde William Gilbert até experimentos realizados por Becquerel que mostram a que temperatura os efeitos magnéticos são intensificados nos circuitos termoelétricos propostos por Oersted e Fourier.

Ao finalizar o verbete, Oersted salienta a concepção romântica que explica o eletromagnetismo e as relações entre eletricidade, magnetismo, calor, luz e afinidades químicas, em oposição ao modelo de Ampére.

Nos trabalhos de Oersted relacionados aos resultados de Seebeck fica clara sua tentativa de reforçar a própria teoria eletromagnética. Oersted atribui os efeitos magnéticos observados por Seebeck à presença de uma

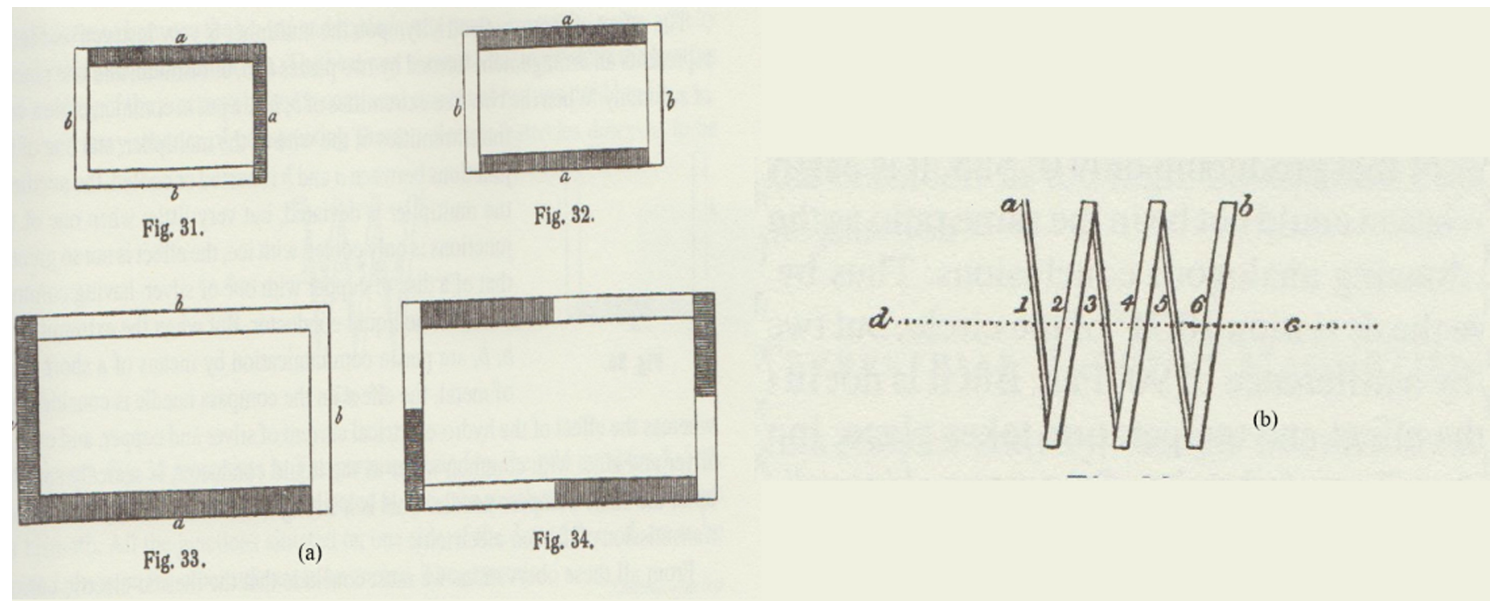

Figura 8: (a) Circuitos termoelétricos montados por Oersted e Fourier. As barras escuras são de bismuto e as claras de antimônio. As junções dos metais são mantidas a diferentes temperaturas. (b) circuito com 22 barras de antimônio $a$ e bismuto $b$, intercaladas. As junções deveriam ser mantidas a diferentes temperaturas. Fonte: Oersted [28, p. 573-575]. 
eletricidade fluindo através dos metais, devido à diferença de temperatura. Ele utiliza apenas aqueles resultados que podem ser convenientes para corroborar seu eletromagnetismo.

Assim como já havia feito com o multiplicador de Schweigger, Oersted não somente descreveu os instrumentos e experimentos relacionados ao eletromagnetismo, como também fez alterações que fortaleciam sua própria teoria e ajudavam na sua aceitação perante a comunidade científica. Para obter a aceitação, Oersted modificou os achados e conclusões tentando torná-los mais descritivos e familiares para o público.

Em relação a Seebeck, Caneva [31, p. 329] argumenta que para a comunidade científica foi mais fácil substituir a ideia de efeito termomagnético, que não poderia ser bem explicada naquele momento, pelo efeito termoelétrico apresentado por Oersted como uma analogia à pilha de Volta, que já era mais aceita e tinha sido como uma grande invenção. A forma como a divulgação do trabalho de Seebeck foi feita acabou por definir se o efeito se tratava de termoeletricidade ou termomagnetismo.

Portanto, trata-se de um exemplo histórico de que as distorções ocorreram pelos próprios cientistas - no caso, Oersted - numa tentativa de favorecer interesses pessoais. Não há registros de trabalhos posteriores de Seebeck se opondo a Oersted. Quando Oersted publicou seu verbete sobre termoeletricidade, fez na verdade uma apologia à sua própria teoria eletromagnética, usando o trabalho de Seebeck apenas para corroborá-la.

\section{A interpretação atual}

A forma como Oersted divulgou o trabalho de Seebeck também trouxe consequências para a interpretação atual do efeito e o modo como ele é discutido no ensino de ciências.

O efeito Seebeck, como é conhecido atualmente, está associado a termopares e à produção de corrente elétrica quando há diferença de temperatura. Experimentos envolvendo efeito Seebeck restringem-se à medição de corrente e/ou tensão elétrica entre dois recipientes que compõe um circuito elétrico e onde estão localizados os termopares. Geralmente são realizados em classes de física térmica ou relacionadas à transformação de energia $[32,33]$.

Kits comerciais para laboratório didático disponíveis no mercado são constituídos de: termopar calibrado para medida de temperatura, multímetro, béquer para água quente e fria, termômetros e suporte. Como parte do roteiro experimental, os alunos devem: averiguar temperaturas e verificar a resistência do termopar, medir a tensão de acordo com a temperatura, elaborar gráfico de tensão por diferença de temperatura, determinar o coeficiente Seebeck.

O procedimental experimental difere em muito dos experimentos históricos realizados por Seebeck e Oersted. Os roteiros de laboratório induzem os alunos a buscarem por uma relação matemática de proporcionalidade, sem que sejam estimulados a investigar quais variáveis interferem nos resultados. Além disso, a medição do efeito Seebeck de acordo com seu significado original implicaria em medidas magnéticas, e não elétricas. Portanto, não seria o caso de utilizar um multímetro para medir corrente/tensão elétrica, mas de uma bússola para medir o ângulo de deflexão quando as extremidades do termopar (junção de dois metais) se encontram a temperaturas diferentes.

Não há, porém, uma bússola nos kits didáticos. Isso significa que, implicitamente, já está aceito que a teoria eletromagnética de Oersted é válida e a diferença de temperatura na junção dos metais produz efeitos elétricos. A princípio, pode parecer uma modificação irrelevante. Mas assumir uma teoria como válida antes mesmo da obtenção dos resultados não é utilizar as aulas experimentais para estimular na investigação. Desta forma a experimentação serve apenas para corroboração de verdades aceitas sem questionamento, reproduzindo uma visão positivista e empirista da ciência.

\section{Considerações finais}

O estudo de caso histórico associado ao efeito Seebeck é um bom exemplo de como os conceitos científicos podem mudar ao longo dos anos e de acordo com os interesses sociais. Mesmo os propósitos científicos são modificados de acordo com seus divulgadores. A forma como Oersted divulgou os resultados de Seebeck, destacando apenas aquilo que atendia à sua própria teoria, alterou-o conceitualmente. Ao invés de uma relação entre magnetismo e calor, passou-se a obter uma relação entre eletricidade e calor, em que já está implícito que efeitos magnéticos são transversais à corrente elétrica.

Além disso, os pressupostos de Oersted e de Seebeck estavam baseados na concepção romântica de natureza (Naturphilosophie) que considerava como certa a transformação das forças. Esta concepção influenciou não somente nos estudos de eletromagnetismo, mas também nas ideias de conservação de energia $[11,12]$. Portanto, abordar esses pressupostos, bem como as relações de interesse entre os cientistas, permite contextualizar melhor a ciência e explorar sua interdisciplinaridade.

O mesmo ocorre quanto à reprodução de experimento históricos. Uma investigação experimental adotando os pressupostos de Seebeck levaria a um estudo mais detalhado de variáveis como área de contato, forma, tamanho e volume, e propriedades da matéria. Isso implicaria em buscar por relações, investigar diferentes variáveis e, talvez, chegar a resultados muito mais interessantes do que aqueles que pede o roteiro de laboratório.

Enquanto que, ao medir apenas variáveis elétricas, tanto o conceito quanto o significado dos experimentos realizados por Seebeck ficam distorcidos. Também fica distorcida a própria ciência, que é vista apenas como uma reprodução de resultados que "deram certo". 


\section{Agradecimentos}

A autora agradece à Coordenação de Aperfeiçoamento de Pessoal de Nível Superior (CAPES) pelo financiamento (processo 88881.172857/2018-01), e aos professores Jan Frercks e Peter Heering, da Europa-Universität Flensburg, pela ajuda com as fontes originais e com os experimentos.

\section{Referências}

[1] L.A.P. Martins, Ciência \& Educação 11, 2 (2005).

[2] A.F.P. Martins, Caderno Brasileiro de Ensino de Física 32, 3 (2015).

[3] D. Allchin, Canadian Journal of Science, Mathematics and Technology Education 17, 1 (2017).

[4] T.C.M. Forato, M. Pietrocola e R.A. Martins, Caderno Brasileiro de Ensino de Física 28, 27 (2011).

[5] R.A. Martins, in: Teaching Science with context: historical, philosophical, and sociological approaches, editado por M.E.B. Prestes e C.C. Silva (Springer, Switzerland, 2018), p. 277.

[6] F. Steinle, Philosophy of Science 64, 65 (1997).

[7] F. Steinle, Perspectives on science 10, 4 (2002).

[8] H. Fors, L.M. Principe e H.O. Sibum, AMBIX 63, 2 (2016).

[9] H.C. Ørsted, Annals of Philosophy, 16, 273 (1820).

[10] R.A. Martins, Cadernos de História e Filosofia da Ciência 10, 89 (1986).

[11] K.L. Caneva, History of science 35, 1 (1997).

[12] A.P.B. Silva e J.A. Silva, História, Ciências, SaúdeManguinhos 24, 3 (2017).

[13] H.C. Ørsted, Journal für Chemie und Physik 5, 398 (1812).

[14] R.A. Martins, in: Hans Christian Ørsted and the Romantic Legacy in Science: Ideas, Disciplines, Practices, editado por R.M. Brain, R.S. Cohen e O. Knudsen (Springer, New York, 2007), p. 339.

[15] D. Gardelli, Caderno Brasileiro de Ensino de Física 35, 1 (2018).

[16] D.C. Christensen, Hans Christian Ørsted: reading nature's mind (University Press, Oxford, 2013).

[17] K.L. Caneva, Historical Studies in the Physical Sciences 9, 63 (1978).

[18] E. Cavicchi, American Journal of Physics 71, 2 (2003).

[19] R.A. Chipman, Bulletin Smithsonian Institution 240, 38 (1966).

[20] H.C. Ørsted, Annals of Philosophy 5, 436 (1823).

[21] K. Jelved e A.D. Jackson, The travel letters of $H$. C. Ørsted (Det Kongelige Danske Videnskabernes Selskab, Denmark, 2011).

[22] K. Nielsen, Historical Studies in the Physical and Biological Sciences 21, 2 (1991).

[23] Royal Society of London, Catalogue of scientific papers (1800-1863) V, London (1871).

[24] T.J. Seebeck, Abhandlungen der physikalischen Klasse der Königlich-Preußischen (G. Reimer, Berlin, 1822), p. 289.

[25] T.J. Seebeck, Ostwald's Klassiker der Exakten Wissenschaften 70, 1 (1895).
[26] T.J. Seebeck, Abhandlungen der physikalischen Klasse der Königlich-Preußischen (G. Reimer, Berlin, 1825), p. 265.

[27] E.J.B. Ferreira e A.P.B. Silva, Cad. Bras. Ens. Física 33, 861 (2016).

[28] H.C. Ørsted, Selected scientific works of Hans Christian Ørsted (Princeton University Press, Princeton, 1998).

[29] P. Barlow, Phil. Trans. R. Soc. Lond. 121, 99 (1831).

[30] H.C. Ørsted e B. Fourier, Annales de chimie et de physique 22, 375 (1823).

[31] K.L. Caneva, in: Hans Christian Ørsted and the Romantic Legacy in Science: Ideas, Disciplines, Practices, editado por R.M. Brain, R.S. Cohen e O. Knudsen (Springer, New York, 2007), p. 273.

[32] A.R. Garcia, D.A. Ulibarreba, A.M. Echeverri, P.A. Garacochea e G.P Artieda, Journal of Technology and Science Education 3, 3 (2013).

[33] A. Molki, Science Education Review 9, 3 (2010). 